\title{
Adição de piruvato de sódio e trolox ao diluidor utilizado para congelação de sêmen de garanhões férteis e subférteis
}

\author{
Effect of pyruvate and trolox added to the extender used for freezing fertile and subfertile stallion \\ semen
}

\author{
Karen Mascaro Gonçalves da Silva'* Sandra Cristina Gamboa' Ana Sofia Rodrigues ${ }^{\mathrm{III}}$ \\ João Ramalho Santos ${ }^{\mathrm{III}}$ Maria Madalena Pessoa Guerra ${ }^{\mathrm{I}}$
}

\section{RESUMO}

O objetivo deste trabalho foi avaliar o efeito do piruvato e trolox (forma solúvel da vitamina E) sobre a qualidade espermática pós-descongelamento. Assim, com o intuito de proteger as células espermáticas dos efeitos deletérios da criopreservação,foram considerados os seguintes tratamentos: T1 $($ Controle $)=$ INRA82-HEPES sem antioxidantes; T2= INRA82-HEPES + 2mM de piruvato e T3= INRA82-HEPES + $120 \mathrm{mM}$ de trolox. As amostras de sêmen descongeladas foram avaliadas quanto à motilidade total (MT) e progressiva (MP), a integridades de membrana plasmática e acrossômica, integridade do DNA, à estabilidade de membrana e ao potencial de membrana mitocondrial $(\Delta \Psi m)$. A adição de piruvato proporcionou resultados superiores $(P<0,05)$ àqueles obtidos com trolox na motilidade espermática total (9,17 e 14,5\%, respectivamente). A adição de piruvato incrementa a motilidade espermática (18,92 e 19,0\%, respectivamente) em garanhões férteis e subférteis submetidos à congelação.

Palavras-chave: trolox, piruvato, congelação, viabilidade espermática, eqüino.

\section{ABSTRACT}

The objective of this research was to evaluate the effect of pyruvate and trolox on the thawed sperm quality. For freezing, antioxidants were added to INRA 82-HEPES extender to protect sperm from the deleterious effects of oxidative stress, according to the treatments: T1 = INRA82-HEPES without antioxidants; T2 = INRA82-HEPES $+2 \mathrm{mM}$ of pyruvate and T3= INRA82-HEPES + $120 \mathrm{mM}$ de trolox. The thawed semen samples were evaluated according to the total (MT) and progressive (MP) motility, integrity of plasma and acrossomal membrane, DNA integrity, membrane stability and mitochondrial membrane potential $(\Delta \Psi \mathrm{\Psi})$ ). It was observed that the addition of pyruvate resulted in a significantly higher total sperm motility $(P<0.05)$ to those obtained with trolox (9.17 and $14.5 \%$, respectively). It can be concluded that the addition of pyruvate improves sperm motility (18.92 and 19.0\%, respectively) in samples from fertile and sub-fertile stallions submitted to freezing.

Key words: trolox, pyruvate, freezing, spermatic viability, equine.

\section{INTRODUÇÃO}

Sabe-se que o garanhão é um reprodutor de dias longos e que a qualidade espermática pode ser influenciada de forma negativa fora do período reprodutivo. Apesar disso, em regiões de clima marcadamente distinto, a época de menor luminosidade pode ser o melhor período para a criopreservação, sendo que a viabilidade dessas células espermáticas póscongelação pode variar não apenas devido ao clima, mas também pode sofrer influência do ejaculado e do garanhão.

Os espermatozóides possuem a capacidade inerente de produzir espécies reativas ao oxigênio (ROS), responsáveis por alterações espermáticas indispensáveis ao processo de fertilização. Entretanto, a produção excessiva de ROS determina estresse

'Departamento de Medicina Veterinária, Universidade Federal Rural de Pernambuco (UFPE), 52171-900, Recife, PE, Brasil. Email: karenmascaro1@hotmail.com.*Autor para correspondência.

"Laboratório de Reprodução Animal, Departamento de Ciências Zootécnicas, Escola Superior Agrária, Instituto Politécnico de Coimbra, Portugal.

IIIDepartamento de Zoologia, Centro de Neurociência e Biologia Celular de Coimbra, Universidade de Coimbra, 3004-517, Coimbra, Portugal. 
oxidativo que prejudica a sobrevivência e a manutenção da capacidade fertilizante desses gametas (GUERRA et al., 2004). Alguns procedimentos utilizados em laboratório para a congelação aumentam a produção de ROS (CEROLINI et al., 2001).

Em mamíferos, as membranas espermáticas são ricas em ácidos graxos poliinsaturados, tornandoas susceptíveis a danos peroxidativos induzidos por radicais livres (SIKKA, 2004), determinando perda de suas funções (CHRISTOVA et al., 2004) e da integridade do DNA (BAUMBER et al., 2003), além de depleção de ATP e perda de motilidade espermática (De LAMIRANDE et al., 1997).

Visando reduzir danos oxidativos causados pela elevada concentração de ROS, alguns pesquisadores têm adicionado substâncias antioxidantes em amostras de sêmen de várias espécies, inclusive eqüinos (BRUEMMER et al., 2001; ALMEIDA \& BALL, 2005). O ânion piruvato tem sido conhecido como captador de peróxido de hidrogênio nos sistemas celulares, promovendo proteção contra danos oxidativos, considerado ainda como excelente substrato energético que pode se mover livremente no citoplasma e nas mitocôndrias da célula (UPRETI et al., 1997) e na dose de 2mM melhorou a motilidade de sêmen resfriado de eqüino (BRUEMMER et al., 2001). A vitamina $E$ ( $\alpha$-tocoferol e seus derivados) protege as células de radicais de oxigênio, in vivo e in vitro, e acredita-se que ela é o inibidor primário de radicais livres encontrados em pequenas quantidades nas membranas celulares e no plasma seminal de mamíferos (SIKKA, 2004). O trolox, na dosagem de $120 \mathrm{mM}$, promoveu melhora na motilidade espermática de sêmen resfriado de eqüino em experimento prévio, ratificando sua ação como antioxidante.

O objetivo deste trabalho foi avaliar o efeito do piruvato e do trolox (forma solúvel da vitamina E) sobre a qualidade espermática pósdescongelamento.

\section{MATERIAL E MÉTODOS}

O estudo foi realizado durante a estação reprodutiva (primavera-verão) no hemisfério norte, região de clima mediterrâneo. As amostras de sêmen foram obtidas de cinco garanhões de raças distintas, que permaneceram estabulados na Escola Superior Agrária de Coimbra (Portugal). Os garanhões foram submetidos, no início da época reprodutiva, a exame andrológico e foram classificados como férteis (RF; Puro Sangue Lusitano, Anglo-Árabe, Holstein) e subférteis (RSF; Sorraia e Garrana), de acordo com o exame andrológico e as taxas de prenhez (60,6 e 30,0\%, respectivamente) obtidas com sêmen in natura na época de reprodução.

Cinco ejaculados de cada reprodutor coletados com vagina artificial (modelo INRA) com auxílio de um manequim (modelo Hannover), na presença de uma égua em cio - livres de gel e impurezas foram mantidos a $35^{\circ} \mathrm{C}$, em banho-maria, durante diluição e análise da qualidade espermática. Motilidade total (MT) e motilidade progressiva (MP) foram avaliadas de forma subjetiva sob microscópio óptico com platina aquecida a $35^{\circ} \mathrm{C}$. Concentração espermática foi calculada usando um fotocolorímetro a ${ }^{\mathrm{a}}$ a $546 \mathrm{~nm}$ previamente calibrado e tendo por método de referência contagens em hemocitômetro.

Foi utilizado o kit de viabilidade espermática LIVE/DEAD ${ }^{\circledR b}$ para avaliação da integridade da membrana e da merocianinab. (M540), de acordo com as recomendações do fabricante. A avaliação do potencial mitocondrial ( se JC-1 ${ }^{\text {b }}$, associado ao IP/SYBR-14 (HUO et al., 2002). Foi avaliada a integridade do acrossoma pelo conteúdo do marcado FITC-PSA ${ }^{c}$ (CASEY et al., 1993). Aliquotas $(10 \mu \mathrm{L})$ de sêmen in natura ou descongelado foram armazenadas em tampão TNE $\left(0,877 g\right.$ de $\operatorname{NaCl}^{c}(0,15 \mathrm{M}$, MW 58,44), 0,1576g TRIS.HCl ${ }^{\mathrm{c}}(0,01 \mathrm{M}$, MW 157,6), 37,2mg EDTA.Na ${ }_{2} 2 \mathrm{H}_{2} \mathrm{O}^{\mathrm{c}}$ (1 mM, MW 372,2), pH 7,4 em solução para $100 \mathrm{~mL}) \mathrm{a}-196^{\circ} \mathrm{C}$ para posterior avaliação da integridade de DNA espermático usando o corante laranja de acridina ${ }^{\mathrm{b}}$ (SAILER et al., 1995). Um total de 200 espermatozóides foi contado para cada amostra distinguindo-se: espermatózóides vivos (IP/SYBR$14^{+}$) e mortos ( $\mathrm{IP}^{+} / \mathrm{SYBR}-14^{-}$), espermatozóides com membrana estável (M540) e instável (M540+), células com elevado (个ÄØm) e baixo potencial mitocondrial ( $\downarrow$ ÄØm) e com DNA integro ou não.

Amostras de sêmen (palhetas de 0,5mL e 50x106 células $/ \mathrm{mL}$ ) foram congeladas, pelo método de Palmer84 modificado por VIDAMENT et al. (2001), após adição de antioxidantes: T1=sem antioxidantes (Controle); T2= $120 \mathrm{mM}$ de trolox ${ }^{3}$ e T3=2mM de piruvato $^{\mathrm{b}}$.

Após descongelação ( $35^{\circ} \mathrm{C}, 30$ segundos), duas palhetas de cada reprodutor/dia foram mantidas em banho-maria nesta temperatura $\left(35^{\circ} \mathrm{C}\right)$ e submetidas às avaliações de motilidade e viabilidade espermática, segundo metodologias mencionadas anteriormente.

A análise estatística foi realizada no programa SPSS versão 14.0 (SPSS Inc., Chicago, IL, USA). Os dados foram analisados quanto à normalidade e à homogeneidade de variâncias e foi avaliada a influência do tratamento antioxidante na qualidade do sêmen após descongelação independente do indivíduo ou da fertilidade (ANOVA). As diferenças entre grupos de fertilidade para cada um dos parâmetros 
espermáticos estimados após descongelação e para cada tratamento foram avaliadas pelo teste $t$ de Student.

\section{RESULTADOS}

Diferenças $(\mathrm{P}<0,05)$ para a MT e MP após coleta foram observadas entre os grupos de fertilidade $(\mathrm{RF}=63,2 \% \pm 12,6$ e 49,7\% \pm 17,6, respectivamente, $\mathrm{e}$
$\mathrm{RSF}=33,0 \% \pm 12,7$ e $18,5 \% \pm 12,2$, respectivamente). Todavia, após a descongelação, estes parâmetros reduziram $(\mathrm{P}<0,05)$ nos ejaculados de todos os garanhões, sem evidenciarem diferença estatística significativa entre os grupos de fertilidade. Ao se avaliar a MT, pós-descongelação, considerando os grupos de fertilidade e os tratamentos utilizados (Figura 1a), foi observado que os porcentuais das amostras coletadas

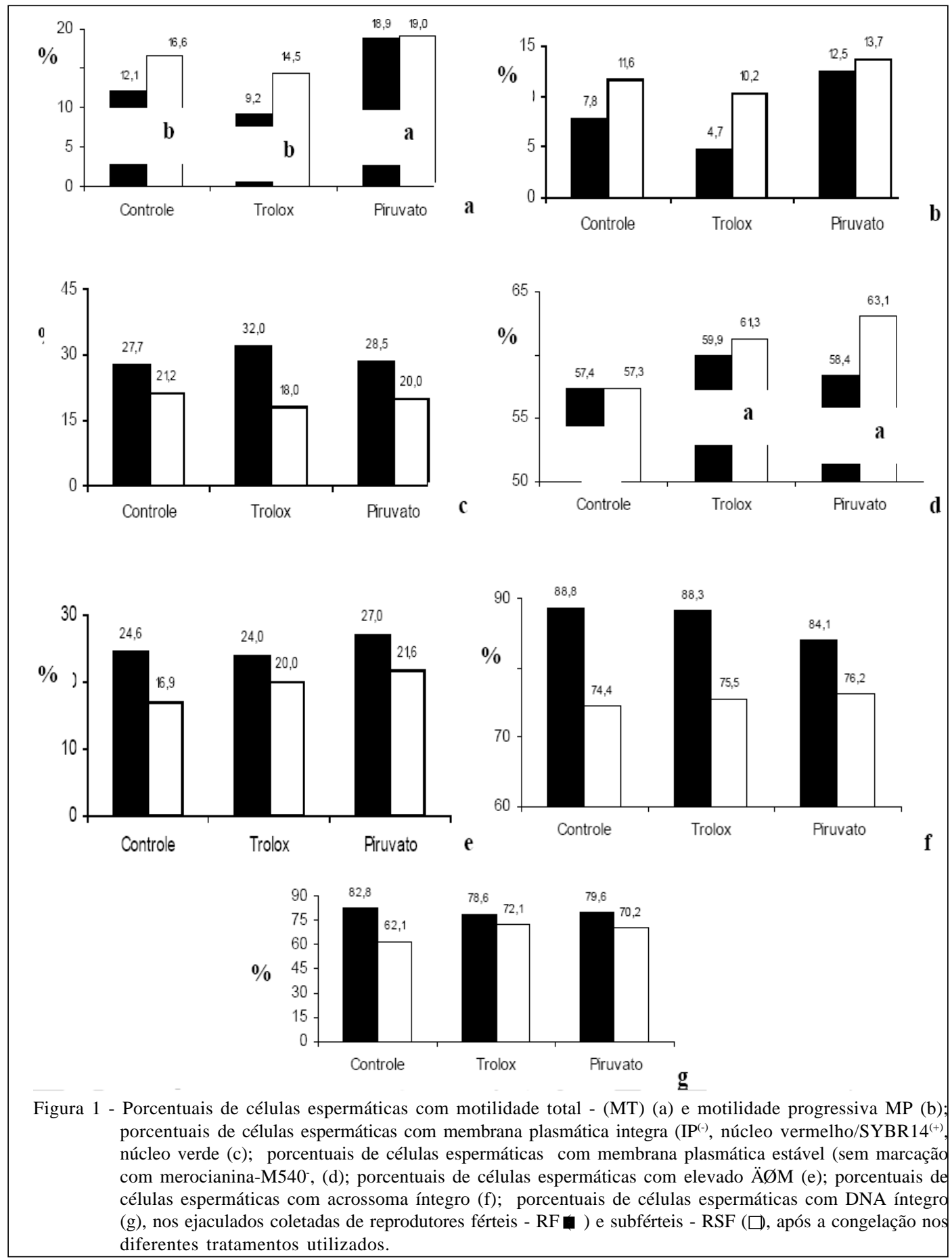

Ciência Rural, v.38, n.8, nov, 2008. 
tanto de RF quanto RSF foram superiores $(\mathrm{P}<0,05)$ para o T2 em relação ao T1 e ao T3. Todavia, não foram encontradas diferenças significativas entre os RF e os RSF para a MP nos diferentes tratamentos (Figura 1b).

Diferenças $(\mathrm{P}<0,05)$ no sêmen in natura entre os RF $(72,2 \% \pm 8,8)$ e os RSF $(55,0 \%+9,5)$ foram observadas para integridade de membrana espermática (IP/SYBR-14). Contudo, pós-descongelação e dentro de cada grupo de fertilidade, não foram observadas diferenças entre os tratamentos (Figuras 1c e 2A $\mathrm{A}$ $2 \mathrm{~A}_{2}$ ). Quanto à avaliação da estabilidade de membrana, não se evidenciaram diferenças significativas entre os grupos de fertilidade, tanto para o sêmen in natura $(80,6 \% \pm 5,5$ e $60,6 \% \pm 13,5$ para RF e RSF, respectivamente) quanto para os diferentes tratamentos. No entanto, em ambos os grupos de fertilidade, o porcentual de células M540- conservadas com antioxidantes (T2 e T3) foi superior ao verificado no Controle (T1). Curiosamente, no grupo RSF os valores médios encontrados são superiores aos do RF tanto para o T2 como para o T3, sendo que com piruvato essa superioridade é numericamente elevada apesar de a ANOVA não evidenciar diferenças significativas (Figura 1d).

O porcentual de células com elevado potencial de membrana mitocondrial (个 ӒØm) nas amostras de sêmen in natura dos RF $(66,7 \% \pm 11,9)$ foi superior $(\mathrm{P}>0,05)$ ao observado nos $\operatorname{RSF}(46,5 \% \pm 19,1)$. No entanto, após a congelação-descongelação, as amostras sem antioxidantes evidenciaram valores significativamente inferiores $(\mathrm{P}<0,05)$ aos do sêmen in natura nos dois grupos de fertilidade. Todavia, tanto
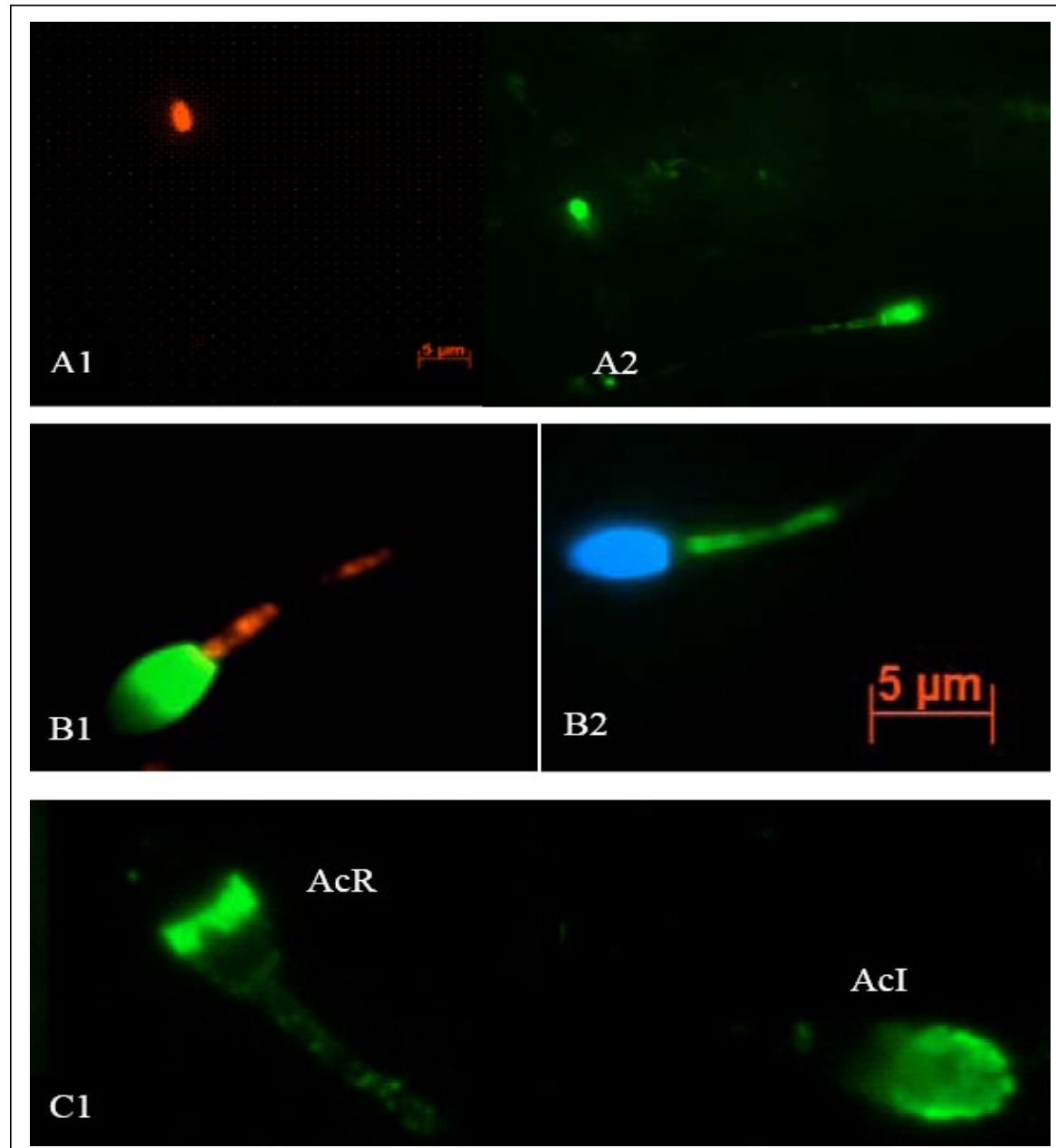

Figura 2 - $\mathrm{A}_{1}$ - espermatozóide com membrana plasmática lesada (IP+, vermelho). $\mathrm{A}_{2}$ espermatozóides com membrana plasmática íntegra ( $\mathrm{SYBR}+$, verde); $\mathrm{B}_{1}{ }_{-}^{-}$ espermatozóides com alto potencial mitocondrial (peça intermediária vermelha, núcleo corado de SYBR, verde); $B_{2}$ - espermatozóides com baixo potencial mitocondrial (peça intermediária verde, núcleo corado de DAPI, azul), avaliados por meio de JC-1; $\mathrm{C}_{1}$ - espermatozóides com acrossoma reagido (AcR) e acrossoma intacto (AcI), corados com FITC-PSA.

Ciência Rural, v.38, n.8, nov, 2008. 
para o RF como para o RSF não foi observada diferença estatística significativa entre os tratamentos utilizados (Figura 1e e 2B e $2 \mathrm{~B}_{2}$ ).

Os dois grupos de fertilidade não diferiram nos porcentuais elevados de acrossomas íntegros no sêmen in natura $(\mathrm{RF}=82,6 \% \pm 9,1 ; \mathrm{RSF}=81,2 \% \pm 9,3)$ contrariamente ao sêmen descongelado em que foram evidenciadas diferenças $(\mathrm{P}<0,05)$ entre RF e RSF. Contudo, em cada grupo de fertilidade, os tratamentos não diferem (Figuras 1f e 2C1).

Quanto à integridade do DNA, no sêmen in natura não foi evidenciada diferença estatística significativa entre os grupos RF $(89,4 \% \pm 17,2)$ e RSF $(81,2 \% \pm 9,3)$ contrariamente ao sêmen descongelado, em que o porcentual de espermatozóides com DNA íntegro no $\mathrm{T} 1$ foi superior $(\mathrm{P}<0,05)$ nos animais férteis. Em nenhum dos grupos de fertilidade considerados foi observada diferença estatística entre os tratamentos (Figura 1g).

\section{DISCUSSÃO}

Motilidade total e progressiva, integridade e estabilidade de membrana, potencial de membrana mitocondrial e integridade acrossomal evidenciaram diferença estatística significativa entre amostras de sêmen coletadas de RF e RSF, ratificando a classificação destes animais quanto à sua taxa de fertilidade. Da mesma forma, foi constatado que, com exceção dos porcentuais de células com acrossoma e DNA íntegros, todos os parâmetros das amostras de sêmen coletadas durante a primavera/verão demonstraram redução acentuada após o procedimento de congelação, atingindo porcentuais abaixo daqueles obtidos após a congelação de sêmen eqüino indicados pelo Manual para Exame Andrológico do Colégio Brasileiro de Reprodução Animal (CBRA, 1998).

Existem diferenças na estrutura e na integridade funcional do acrossoma e da membrana plasmática decorrentes de alterações circanuais na composição do plasma seminal que interferem na membrana espermática (HOFFMAN \& LANDECK, 1999). Apesar de a congelação ter sido realizada em um período que alguns autores relatam não ser apropriado (MAGISTRINI et al., 1987), esperava-se que a adição das substâncias antioxidantes como trolox e piruvato melhorassem a qualidade de alguns parâmetros seminais de amostras congeladas, uma vez que estas substâncias atuam como antioxidantes não-enzimáticos (SILVA, 2006).

Os espermatozóides necessitam de energia para superar o estresse do processo de congelação/ descongelação (FABBROCINI et al., 2000). Segundo
BRUEMMER et al. (2001), a adição de 2mM de piruvato ao sêmen refrigerado de eqüino melhorou a motilidade espermática. Os resultados deste experimento corroboram esses autores, uma vez que foi constatado aumento no porcentual de células móveis após a adição de piruvato, independente da fertilidade. Já a adição de trolox não determinou qualquer efeito benéfico na MT e na MP após a descongelação, assim como também não revelou qualquer influência na manutenção da topologia da membrana nos reprodutores com problemas de fertilidade, contrariamente aos férteis. A integridade de membrana em amostras de sêmen fresco e descongelado de várias espécies é indicativa do potencial fertilizante destas células (BRINSKO et al., 2000). Este experimento sugere que o trolox associado ao piruvato poderá ser interessante nos meios diluidores de congelação, pois, se o primeiro preservou a integridade de membrana nos espermatozóides dos RF, o segundo mantém a ordem de membrana mais acentuadamente nos RSF do que nos RF. Curiosamente, nenhum destes antioxidantes se revelou eficaz na protecção às mitocôndrias durante o processo de congelação/descongelação. Todavia, o piruvato, por ser um substrato energético, parece manter uma melhor funcionalidade mitocondrial. Isso também parece explicar o fato de de que os porcentuais de células com acrossomas íntegros utilizando piruvato sejam inferiores ao controle e ao T3 no grupo dos RF (Figura 1).

Foi constatada correlação positiva entre o aumento do porcentual de dano espermático, indicado pelo aumento do estresse oxidativo, e a apoptose mediada por caspase em pacientes com fator de infertilidade masculina (WANG et al., 2003). Assim, antioxidantes utilizados com o objetivo de reduzir ou inibir a produção de espécies reativas ao oxigênio (ROS) podem determinar menos apoptose e, assim, aumentar a qualidade espermática por meio da redução de danos ao DNA. O fato de a melhora na integridade do DNA ter ocorrido apenas nos espermatozóides de RSF concorda com DONELLY et al. (1999), ao relatarem que a adição de ascorbato ou $\alpha$-tocoferol na preparação do meio diluidor não apresentou efeito positivo quando os espermatozóides possuíam $\geq 80 \%$ DNA íntegros, apesar desses antioxidantes promoverem decréscimo na produção de ROS.

A motilidade espermática eqüina pode ser afetada por um mecanismo de ação de ROS, independente da peroxidação lipídica e das funções dependentes da membrana mitocondrial (BAUMBER et al., 2000). Talvez isso explique o fato de que a adição de piruvato tenha causado efeito positivo apenas na motilidade total dos 
espermatozóides, pois se trata de um substrato energético, sendo sua ação como antioxidante limitada por não ter causado melhora em outros parâmetros seminais testados.

Quando ocorre desequilíbrio na concentração de ROS, observa-se redução na capacidade fertilizante dos espermatozóides. $\mathrm{Na}$ literatura ainda não existe consenso quanto à dosagem e ao tipo de antioxidante ideal para cada espécie. Talvez pelo fato de utilizarem metodologias variadas, formas diferentes de avaliação espermática e diferenças na congelabilidade do sêmen quanto à raça e aos ejaculados dos animais.

\section{CONCLUSÕES}

Piruvato preserva a motilidade espermática total em garanhões férteis e subférteis e os antioxidantes piruvato e trolox utilizados na dosagem 2mM e 120mM, respectivamente, não preservam os parâmetros seminais de eqüinos submetidos à congelação/ descongelação. Provavelmente outros fatores terão interferido de forma negativa na qualidade seminal póscongelação que não apenas a ação de ROS. Novas pesquisas no período de inverno são necessárias para uma melhor avaliação da ação desses antioxidantes na preservação da viabilidade espermática de garanhões.

\section{AGRADECIMENTOS}

Ao Conselho Nacional de Desenvolvimento Científico e Tecnológico (CNPq), pela bolsa de estudo durante a realização do doutorado; à Comissão de aperfeiçoamento de Pessoal de Nível Superior (Capes), pela concessão de bolsa de estudo para realização de Doutoramento sanduíche; à Universidade de Coimbra e ao Instituto Politécnico de Coimbra - Escola Superior Agrária de Coimbra, pela assistência científica e pelo uso dos garanhões.

\section{FONTES DE AQUISIÇÃO}

a - Ciba-corning (Ramsey, MN, USA).

b - Molecular Probes Inc. (Eugene, OR, USA).

c - Sigma (Saint Louis, MO, USA).

\section{REFERÊNCIAS}

ALMEIDA, J.; BALL, B.A. Effect of $\alpha$-tocopherol and tocopherol succinate on lipid peroxidation in equine spermatozoa. Animal Reproduction Science, v.87, p.321337, 2005.

BAUMBER, J. et al. The effect of reactive oxygen species on equine sperm motility, viability, acrossomal integrity, mitochondrial membrane potential, and membrane lipid peroxidation. Journal of Andrology, v.21, n.6, p.895-901, 2000.
BAUMBER, J. et al. Reactive oxygen species and cryopreservation promove DNA fragmentation in equine spermatozoa. Journal of Andrology, v.24, p.621-628, 2003.

BRINSKO, S.P. et al. Motility, morphology, and triple stain analysis of fresh, cooled, and frozen-thawed stallion sperm. Journal of Reproduction and Fertility Suppl, v.56, p.111120,2000 .

BRUEMMER, J.E. et al. Effect of pyruvate on the function of stallion spermatozoa stored for up to 48 hours. Journal of Animal Science, v.80, p.12-18, 2001.

CASEY, P.J. et al. Validation of an acrosomal stain for equine sperm that differentiates between living and dead sperm. Journal of Andrology, v.14, p.289-297, 1993.

CEROLINI, S. et al. Changes in sperm quality and lipid composition during cryopreservation of boar semen. Reproduction, v.121, p.395-401, 2001.

CHRISTOVA, Y. et al. Lipid difusión in sperm plasma membranas exponed to peroxidative injury from oxygen free radicals. Molecular Reproduction and Development, v.68, p.365-372, 2004.

De LAMIRANDE, E. et al. Reactive oxygen species and sperm phisiology. Journal of Reproduction and Fertility, v.2, p.48-54, 1997.

DONNELLY, E.T. et al. The effect of ascorbate and $\alpha$-tocoferol supplementation in vitro on DNA integrity and hydrogen peroxide-induced DNA damage in human spermatozoa. Mutagenesis, v.14, n.5, p.501-511, 1999.

FABBROCINI, A. et al. Effect of diferencial addition of glycerol and pyruvate to extender on cryopreservation of mediterranean buffalo (B. bubbalis) spermatozoa. Theriogenology, v.54, p.193-207, 2000.

GUERRA, M.M.P. et al. Papel de oxidantes e anti-oxidantes na andrologia (revisão de literatura). Revista Brasileira de Reprodução Animal, v.28, n.4, p.1-9, 2004.

HOFFMANN, B.; LANDECK, A. Testicular endocrine function, seasonality and semen quality of the stallion. Animal Reproduction Science, v.57, p.89-98, 1999.

HUO, L.J. et al. Assessment of sperm viability, mitochondrial activity, capacitation and acrossome intactness in extended boar semen during long-term storage. Theriogenology, v.58, p.1349-1360, 2002.

Manual para exame andrológico e avaliação de sêmen animal. 2.ed. Minas Gerais: Colégio Brasileiro de Reprodução Animal (CBRA), 1998. 49p.

MAGISTRINI, M. et al. Influence of season and frequency of ejaculation on production of stallion semen for freezing. Journal of Reproduction and Fertility Supplement, v.35, p.127-133, 1987.

SAILER, B.L. et al. Mammalian sperm DNA susceptibility to in situ denaturation associated with the present of DNA stand 
breaks as measured by the terminal deoxynucleotidyl transferase assay. Journal of Andrology, v.16, n.1, p.80-87, 1995.

SIKKA, S.C. Role of oxidative stress and antioxidants in andrology and assisted reproductive technology. Journal of Andrology, v.25, p.5-18, 2004

SILVA, P.F.N. Physiology of peroxidation processes in mammalian sperm. 2006. 178f. Tese (Doutorado em Medicina Veterinária) Utrecht University, Faculty of Veterinary Medicine, Utrecht.
UPRETI, G.C. et al. Studies on aromatic amino acid oxidase activity in ram spermatozoa: role of pyruvate as an antioxidant. Animal Reproduction Science, v.51, p.275-287, 1997.

VIDAMENT, M. et al. Advances in cryopreservation of stallion semen in modified INRA82. Animal Reproduction Science, v.68, p.201-218, 2001.

WANG, $\mathrm{X}$. et al. Oxidative stress is associated with increased DNA damage in patients with male factor infertility. Fertility and Sterility, v.80, n.3, p.531-535, 2003 